\title{
Fabrication of Jute-PP and Wood Stock-PP composites and Comparison of their Physico-Mechanical Properties
}

\author{
G.V.Mahajan, Prof. V. S. Aher, Mr. Rajendra Katore \\ a: P.G. Student, AVCOE, Sangamner, Maharashtra, India \\ b: Professor Department of Mechanical Engineering, AVCOE, Sangamner, Maharashtra, India. \\ c: CEO, Ukay Metal Industries Pvt.Ltd., Nasik, Maharashtra, India
}

\begin{abstract}
The present study aims at learning the fabrication and mechanical behavior of hybrid natural fiber composites. Specimens are cut from the fabricated laminate according to the ASTM standards for different experiments. Short jute fiber reinforced polypropylene PP-based composites (50\% fiber by weight) were fabricated using compression molding and the mechanical properties such as tensile strength, tensile modulus, $\%$ elongation at break, flexural strength, flexural modulus, impact strength, heat deflection temperature, water absorption and flammability of the composites were to be evaluated. Then wood stock reinforced PP-based composites (50\% fiber by weight) were fabricated and all mechanical properties were compared with short jutebased composites. Short jute-based composites showed excellent mechanical properties comparable to wood stock-based composites.
\end{abstract}

Keywords: - Jute-PP, Woodstock-PP, Compression molding.

\section{INTRODUCTION}

Natural fibres already have been used the first time 3000 years ago in composite systems in the ancient Egypt, where straw and clay were mixed together to build walls. Over the last decade, polymer composites reinforced with natural fibres have received ever increasing attention, both from the academic world and from various industries. There is a wide variety of different natural fibres which can be applied as reinforcement or fillers.

The most important types of natural fibres used in composite materials are flax, hemp, jute, kenaf, and sisal due to their properties and availability. Jute is an important bast fibre with a number of advantages. Jute has high specific properties, low density, less abrasive behaviour to the processing equipment, good dimensional stability and harmlessness. Jute textile is a low cost eco-friendly product and is abundantly available, easy to transport and has superior drapability and moisture retention capacity. It is widely being used as a natural choice for plant mulching and rural road pavement construction. The biodegradable and low priced jute products merge with the soil after using providing nourishment to the soil. Being made of cellulose, on combustion, jute does not generate toxic gases. Due to jute's low density combined with relatively stiff and strong behavior, the specific properties of jute fibre can compare to those of glass and some other fibres like polypropylene.

Jute fibre is obtained from two herbaceous annual plants, white Corchorus capsularis (white jute) originating from Asia and Corchorus olitorius (Tossa jute) originating from Africa. Next to cotton, it is the second most common natural fibre, cultivated in the world and extensively grown in Bangladesh, China, India, Indonesia, Brazil. The jute plant grows six to ten feet in height and has no branches. The stem of the jute plant is covered with thick bark, which contains the fibres. In two or three month time, the plants grow up and then are cut, tied up in bundles and kept under water for several days for fermentation. Thus, the stems rot and the fibres from the bark become loose. Then the cultivators pull off the fibres from the bark, wash very carefully and dry them in the sun.

Jute is multicelled in structure. The cell wall of a fibre is made up of a number of layers: the so-called primary wall (the first layer deposited during cell development) and the secondary wall, which again is made up of the three layers. As in all lignocellulosic fibres, these layers mainly contain cellulose, hemicellulose and lignin in varying amounts. The individual fibres are bonded together by a lignin-rich region known as the middle lamella.

The jute fibre possesses moderately high specific strength and stiffness. Therefore, it is suitable as reinforcement in a polymeric resin matrix. However, it exhibits considerable variation in diameter along with the length of individual filaments. The properties of the fibre depend on factors such as size, maturity and processing methods adopted for the extraction of the fibre. Properties such as density, electrical resistivity, ultimate tensile strength and initial modulus are related to the internal structure and chemical composition of fibre. $[1,2]$ 
Polypropylene is a polymer which combines versatility with a low price. It is a vinyl polymer and can be made with different tacticities. Polypropylene is commonly made from the monomer propylene by a ZieglerNatta polymerization, the result is an isotactic polymer, in which all the methyl groups are on the same side of the chain. Polypropylene has good mechanical properties as well as low density. It is a non-polar material. The crystallinity is about $60-70 \%$. The crystalline isotactic polypropylene is insoluble in all common solvents at room temperature, it starts swelling and is finally dissolved by specific solvents only at temperatures generally higher than $100^{\circ} \mathrm{C}$. Its tensile strength, surface hardness and stiffness are higher than that of polyethylene. [3]

\section{EXPERIMENTAL}

\section{1) Materials}

Row Jute-PP and Woodstock-PP fiber were purchased from Jindal Fibres Ltd. Ludhiana, India and final composite board will be prepared by compression molding machine. Then specimens are cut to perform various mechanical testing as per ASTM standards.

\section{2) Fabrication of composites}

Jute-PP: Mixing of Jute fiber with polypropylene (Weight \% 50:50) is done homogenously by manual blending. After mixing the fibers, they are passed through a miniature carding machine four times to ensure homogenous blending prior to web formation. The webs are conditioned at $115^{0} \mathrm{C}$ for 24 hours to remove any moisture present. Composite boards are produced from the carded web by using the compression molding machine. Fibrous webs are cut into pieces and placed on the mold. Webs are stacked to get the required weight/unit area of 1200 GSM. The platens are pressed to desired specific pressure and temperature for a predefined time to get molded product. After completion of the compression cycle, the platens are cooled to optimum temperature and then the pressure is released. A sample of composite board so manufactured after compression molding and specimen are cut as per ASTM standards for various mechanical tests. [4]

Wood Stock-PP: The wood is sawn using a laboratory table saw and the Wood sawdust $(400-500 \mu \mathrm{m})$ is collected. The sawdust is then oven dried at $70^{\circ} \mathrm{C}-80^{\circ} \mathrm{C}$ to a moisture content of $3 \%-5 \%$, then stored in polyethylene bag. The particle sizes of the sawdust are in the range between 80 and 100 mesh. Before making composite the sawdust is dried at $105^{\circ} \mathrm{C}$ for about $24 \mathrm{hr}$ until constant weight is reached to obtain $1 \%-2 \%$ moisture content and then keep in a sealed container. The wood dust is compounded with the granules of polypropylene in the co-rotating twin-screw extruder with operating condition, speed of the screw $80 \mathrm{rpm}$, cycle time 3 min temperature up to $190{ }^{\circ} \mathrm{C}$. The operation conditions of the co-rotating twin-screw extruder compounding including extruder barrel temperature at different extruding zones, melt pressure, and screw speed employed for the compounding of both wood dust and PP. The wood dust and the PP are fed through feeders at the extruder. The PP pellets are firstly fed from the main feeding hopper at the end of the extruder, and then the wood dust is fed through a feeder. The extruded strand coming out from the die head is then passed through a water bath and subsequently palletized. The composite formulations are designed as per the mass proportion in percentage. The composition is $50 \mathrm{wt}$. \% of PP while $50 \mathrm{wt} . \%$ of wood dust. Finally the specimens are cut after receiving the composite as per ASTM standards for various mechanical tests. [5]

\section{3) Mechanical Testing}

Tensile, Impact, Flexural, Flammability, heat deflection and water absorption tests were conducted. For each test and type of composites, four specimens were tested and average values were tabulated.

\section{4) Tensile Test}

This test method evaluates the tensile properties of reinforced composites in the form of standard dumbbell-shaped test specimens when tested under defined conditions of pretreatment, temperature, humidity, and testing machine speed. Tensile tests were conducted according to ASTM D 638-01 using a Universal Testing Machine with a cross-head speed of $50 \mathrm{~mm} / \mathrm{min}$. The dimensions of the test specimen were $165 \mathrm{~mm} \times$ $13 \mathrm{~mm} \times 2 \mathrm{~mm}$.

\section{5) Charpy Impact Test}

These test methods are used to determine the resistance of composites to breakage by flexural shock as indicated by the energy extracted from standardized pendulum type hammers, mounted in standardized machines, in breaking standard specimens with one pendulum swing. The results of these test methods are reported in terms of energy absorbed per unit of specimen width. Tests were conducted on specimens having dimensions $127 \mathrm{~mm} \times 12.7 \mathrm{~mm} \times 2.7 \mathrm{~mm}$ according to ASTM D 6110-97 using a Impact tester. 


\section{6) Flexural Test}

This test method determines the flexural properties of reinforced composites in the form of rectangular bars molded directly or cut from sheets. The flexural test is carried out using the same testing machine mentioned above at the cross head speed of $4.1 \mathrm{~mm} / \mathrm{min}$ and specimen of dimension $80 \mathrm{~mm} \times 25 \mathrm{~mm} \times 2.7 \mathrm{~mm}$ according to ASTM D 790-00. The strength and modulus is calculated.

\section{7) Flammability Test}

This test method provides a standard laboratory procedure for measuring and comparing the burning rates of composite materials under specified controlled conditions. The rate of burning is affected by such factors as density, direction of rise, and type and amount of surface treatments. The thickness of the finished specimens must also be taken into account. These factors must be considered in order to compare materials on the same basis. The test was conducted as per ASTM D5132.

A burn rate is calculated from the following formula:

Where,

$$
\mathrm{B}=(60 \times \mathrm{D}) / \mathrm{T}
$$

$\mathrm{B}=$ Burn Rate in millimeter per minute

$\mathrm{D}=$ Length in millimeter the flame travels

$\mathrm{T}=$ Time in seconds for the flame to travel

\section{8) Heat Deflection Temperature Test}

The deflection temperature is a measure of a composites ability to bear a given load at elevated temperatures. The deflection temperature is the temperature at which a test bar, loaded to the specified bending stress, deflects by $0.25 \mathrm{~mm}$. It is used to determine short-term heat resistance. It distinguishes between materials that are able to sustain light loads at high temperatures and those that lose their rigidity over a narrow temperature range. The bars are placed under the deflection measuring device. A load of $1.80 \mathrm{MPa}$ is placed on each specimen. The specimens are then lowered into a silicone oil bath where the temperature is raised at $2^{\circ} \mathrm{C}$ per minute until they deflect $0.25 \mathrm{~mm}$. The test were done according to ASTM D 648 standard for the specimen of dimension $127 \mathrm{~mm}$ x $12.7 \mathrm{~mm}$ x $2.7 \mathrm{~mm}$. [6]

\section{9) Mechanical Properties of the Composites}

\section{RESULT AND ANALYSIS}

Jute-polypropylene (J-PP) and Wood stock-polypropylene (WS-PP) composites (50\% fiber by weight) were made by compression molding. The mechanical properties such as tensile, flexural, impact, flammability and heat deflection test (HDT) of J-PP and WS-PP composites were evaluated and compared. Four specimens were prepared for each composite and average values of all mechanical properties were taken for comparative analysis. The results are presented in following tables. It was found from table 1 and 2 that tensile strength, tensile modulus, \% elongation at break and impact strength of J-PP composite were found to be 444.42 $\mathrm{Kg} / \mathrm{Sq} . \mathrm{cm}, 6382.018 \mathrm{Mpa}, 0.81,45.49 \mathrm{Kj} / \mathrm{Sq} . \mathrm{cm}$ respectively. Specimen found unbroken against flexural testing. On comparing these values with WS-PP composites we observed that J-PP composites gained a significant improvement of the mechanical properties. Further from table 3 it is observed that the Heat Deflection Temperature (HDT) for J-PP composite was $135.1^{\circ} \mathrm{C}$ which is much more than as compared with WS-PP composite. Also the Flammability of J-PP was noted $20.5 \mathrm{~mm}$ which is higher than WS-PP composite.

Table 1

\begin{tabular}{|l|c|c|cc|}
\hline & \multicolumn{4}{|c|}{ Tensile properties } \\
\hline Material & $\begin{array}{l}\text { Strength } \\
\text { (Kg-Sq.cm) }\end{array}$ & $\begin{array}{l}\text { Modulus } \\
(\mathrm{Mpa})\end{array}$ & $\begin{array}{l}\text { \% Elongation at } \\
\text { break }\end{array}$ & at \\
\hline WS-PP & 336.05 & 5624.244 & \multicolumn{2}{|c|}{0.87} \\
\hline J-PP & 444.42 & 6382.018 & 0.81 \\
\hline
\end{tabular}

Table 2

\begin{tabular}{|c|c|c|l|}
\hline & & \multicolumn{2}{|c|}{ Flexural properties } \\
\cline { 3 - 4 } Material & Impact Strength (Kj/Sq.m) & Strength (Kg/Sq.cm) & $\begin{array}{l}\text { Modulus } \\
(\mathrm{Mpa})\end{array}$ \\
\hline WS-PP & 34.01 & 222.81 & 2550.975 \\
\hline J-PP & 45.49 & \multicolumn{2}{|c|}{ Specimen does not break } \\
\hline
\end{tabular}


Table 3

\begin{tabular}{|c|c|c|}
\hline & \multicolumn{2}{|c|}{ Properties } \\
\hline & HDT & Flammability \\
\hline Material & Temperature(Deg. C.) & Burn Rate (mm) \\
\hline WS-PP & 72.8 & 15.23 \\
\hline J-PP & 135.1 & 20.5 \\
\hline
\end{tabular}

10) Test Data Analysis

i) Tensile Test (ASTM D 638-01)

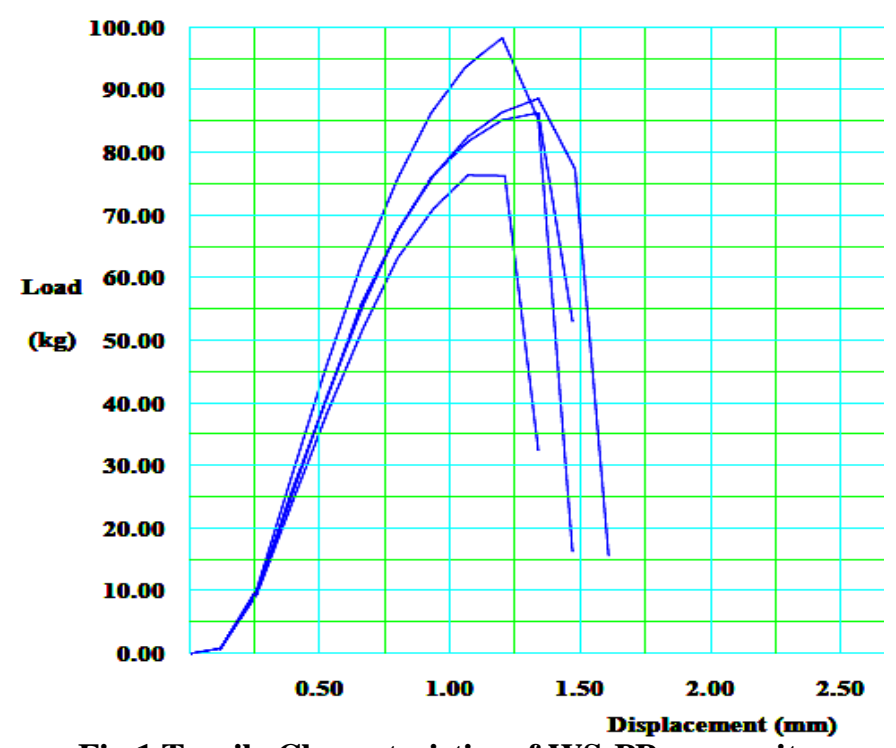

Fig.1 Tensile Characteristics of WS-PP composite

This test method covers the determination of the tensile properties of composites in the form of standard dumbbell-shaped test specimens when tested under defined conditions of pretreatment, temperature, humidity, and testing machine speed. The test was done for four specimens of each composites and result were noted. From Fig. 1 and Fig.2 it is seen that the average value of break load for WS-PP and J-PP were $87.35 \mathrm{Kg}$ and $115.55 \mathrm{Kg}$ respectively. Obviously the tensile strength of J-PP composite greater than that of WS-PP composite.

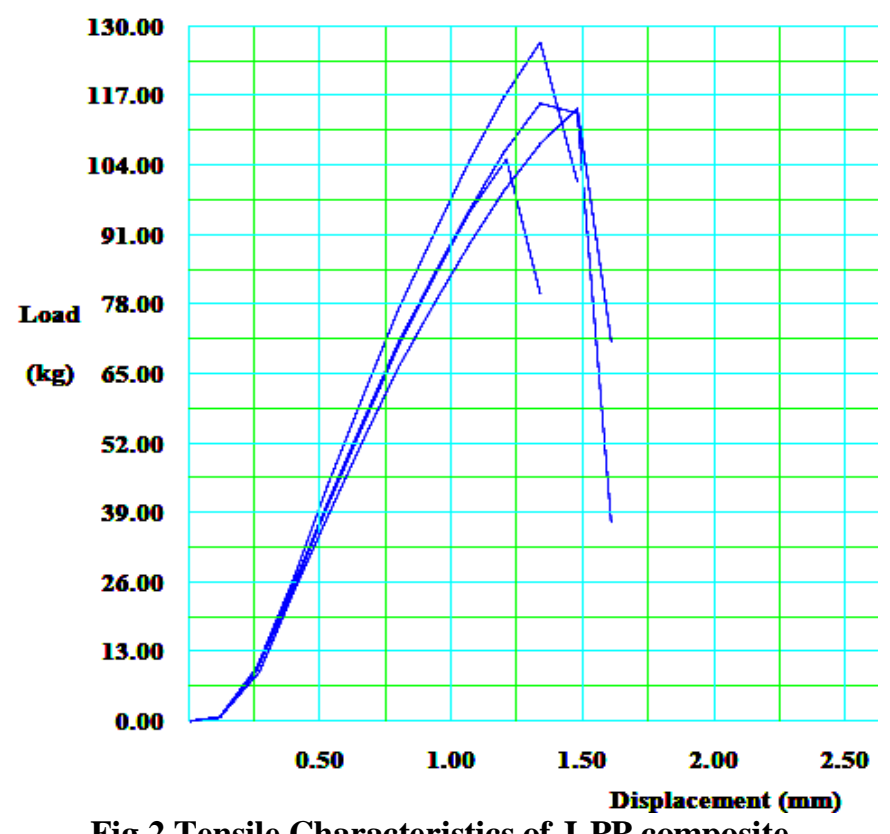

Fig.2 Tensile Characteristics of J-PP composite 
ii) Charpy Impact Test (ASTM D 6110-97)

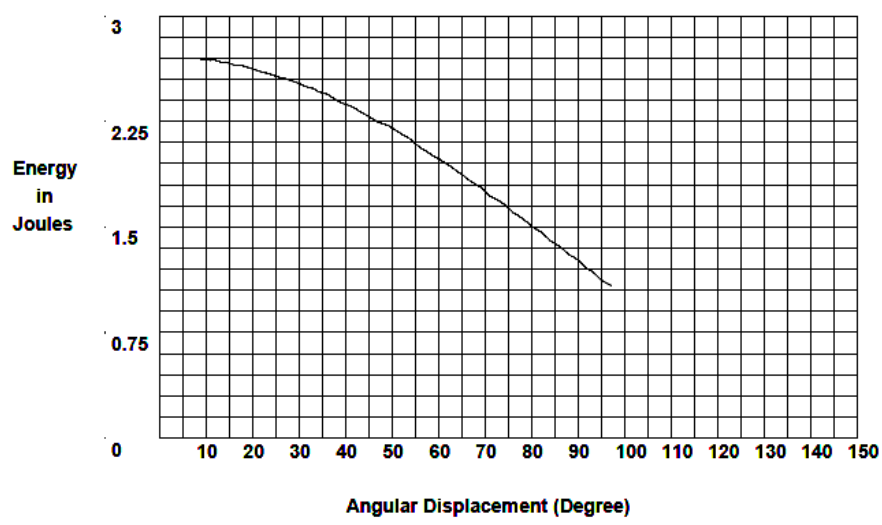

Fig.3 Impact test characteristics of WS-PP composite

This test method includes the determination of the resistance breakage by flexural shock of composites by energy extracted from standardized pendulum type hammer in breaking standard four specimens with one pendulum swing. The result of test was reported in terms of energy absorbed per unit specimen width. From Fig. 3 and Fig.4 it is observed that impact energy for J-PP composite is higher than that of WS-PP composite. Hence Charpy impact strength of J-PP is greater than WS-PP.

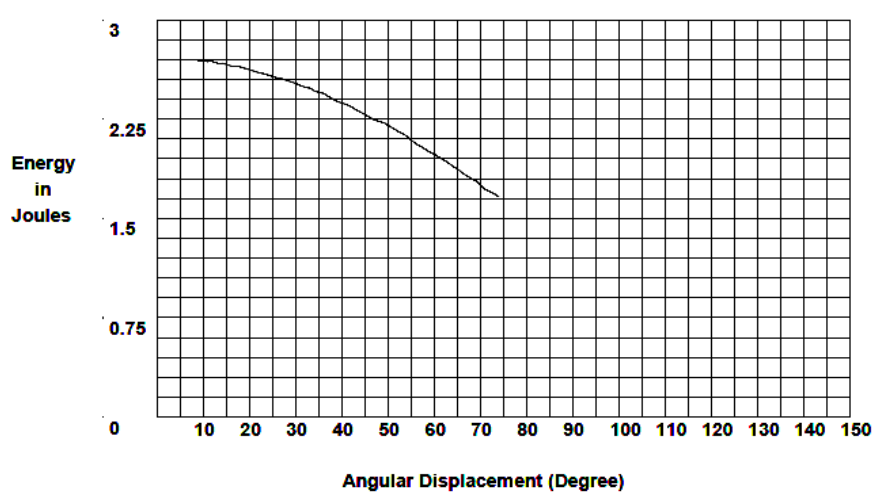

Fig.4 Impact test characteristics of J-PP composite

iii) Flexural Test (ASTM D 790-00)

This method is used to investigate the flexural behavior of composite test specimens and for determining the flexural strength, flexural modulus and other aspects of flexural stress-strain relationship under the defined atmospheric conditions. The load-deflection and stress-strain characteristics for WS-PP composite is shown in Fig.5 and Fig.6 respectively. For J-PP composite the specimens were found unbreakable. Obviously the flexural strength of J-PP was realized much more higher than that of WS-PP composite.

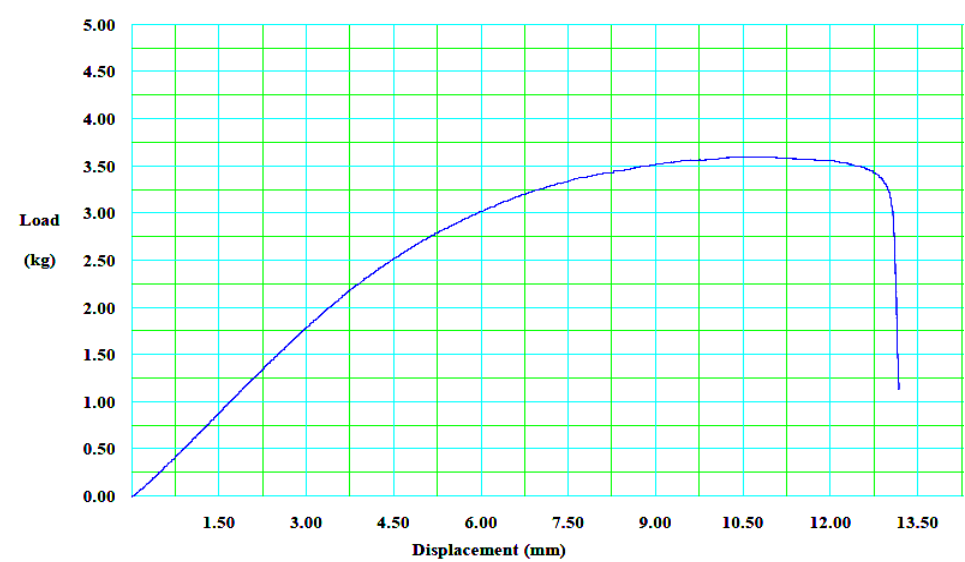

Fig.5 Load-Displacement characteristics for WS-PP composite 


\section{iv) Heat Deflection Temperature Test (ASTM D 648)}

The heat deflection temperature is a measure of a composites ability to bear a given load at elevated temperatures. This method is used to determine the temperature at which the deformation occurs when specimens are subjected to defined set of testing conditions. From Fig.7 and Fig.8 it is seen that the HDT of J-PP is higher than HDT of WS-PP.

\section{CONCLUSION}

We have successfully developed $100 \%$ biodegradable composites with polypropylene as the matrix and jute fibers as reinforcement and without using any chemicals. The J-PP composites fabricated have excellent tensile strength, impact strength, flexural strength, HDT and flammability than WS-PP composites. The J-PP composites could be useful for various applications in automobiles interior components. Further research is in progress to improve the properties of the J-PP composites by varying the percentage of fiber and adding various coupling agents.

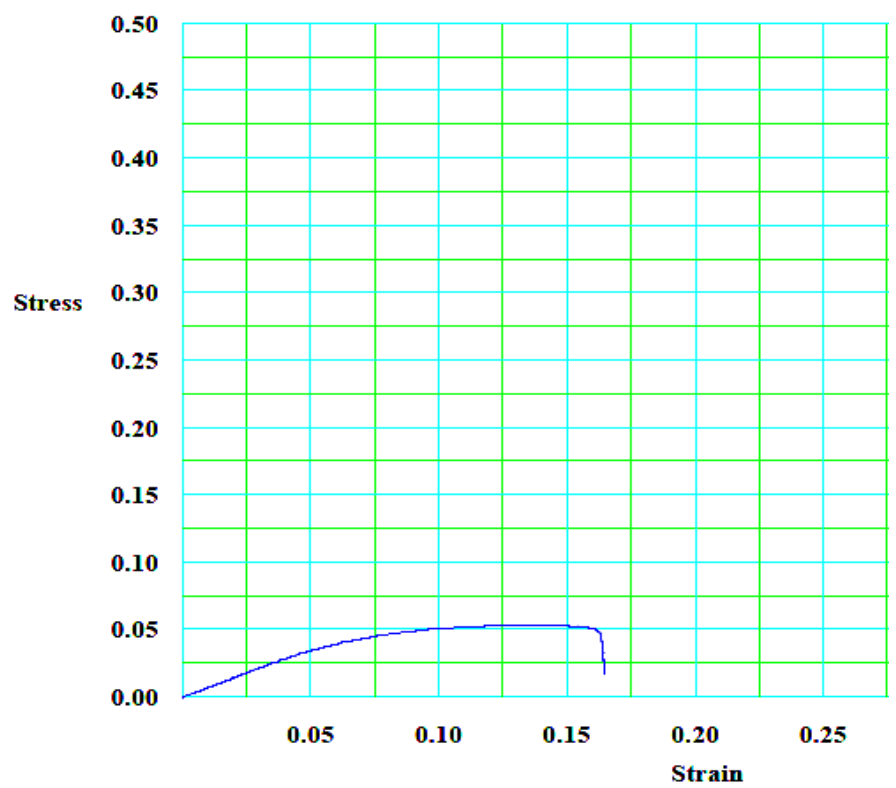

Fig.6 Stress-Strain analysis of WS-PP composite

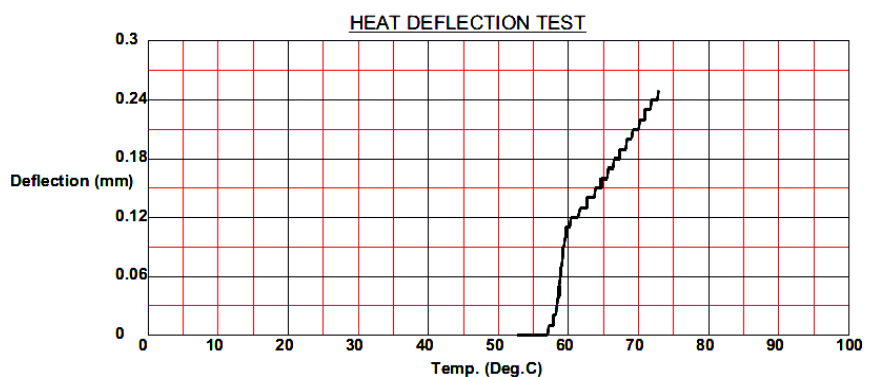

Fig.7 HDT testing of WS-PP composite

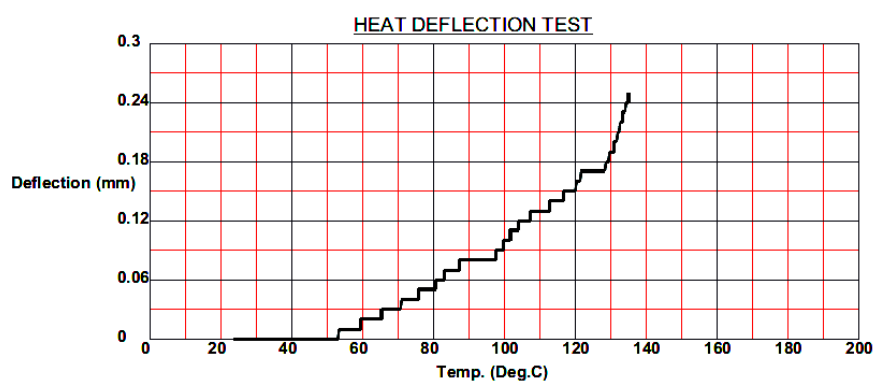

Fig.8 HDT testing of J-PP composite 


\section{REFERENCES}

[1] Md. Rezaur Rehman, Md. Monimul Houque, Md Nazrul Islam "Improvement of PhysioMECHANICAL PROPERTIES OF JUTE FIBRE REINFORCED PROLYPROPYLENE COMPOSITES BY POST TREATMENT" JOURNAL OF COMPOSITES: PART A 39 (2008) 1739-1747.

[2] Pankaj K. Aggarwal, N. Raghu, Ajay Karamarkar, Shakti Chauhan, "Jute Polypropylene composites using M-TMI-grafted Polypropylene as a coupling agent”, Journal of materials and design 43 (2013) 112117.

[3] Sumit Chakraborty, Sarada Prasad Kundu, Aparna Roy, "Improvement of Mechanical properties of jute fibre reinforced cement mortar : A Statistical Approach", Journal of Construction and building materials 38 (2013) 776-784.

[4] Thi-Thu-Loan Doan, Hanna Brodowsky, Edith Ma"der, "Jute fibre/polypropylene composites II. Thermal, hydrothermal and dynamic mechanical behavior", journal of Composites Science and Technology 67 (2007) 2707-2714.

[5] Byung S. Hwang, Byung S. Kim, Jung H. Lee, Joon H. Byun, Jong M. Park, "physical parameters and mechanical properties improvement for jute fiber/polypropylene composites by maleic anhydride coupler", 16th international conference on composite materials.

[6] Ezequiel Parez, Lucia Fama, S.G. Pardo, " Tensile and fracture behavior of PP/wood flour composites" Journal of Composites Part B: 43 (2012) 2795-2800.

[7] Saravannam Kannappan, Bhaarathi Dhurai, "Investigating and Optimizing the Process Variables Related to the Tensile Properties of Short Jute Fiber Reinforced with Polypropylene Composite Board", Journal of Engineered Fibers and Fabrics Volume 7, Issue 4-2012.

[8] J. Bhaskar , S. Haq , A.K.Pandey , N. Srivastava, "Evaluation of properties of propylene-pine wood Plastic composite" Journal of J. Mater. Environ. Sci. 3 (3) (2012) 605-612. 